\title{
Numerical Research on Behaviour of Beams with Different Reinforcement Configurations
}

\author{
Bharanidhar.T.S, P.Eswaramoorthi
}

\begin{abstract}
As the field of infrastructure develops, a large number of structures are built across the country. A major portion of these structures tend to be Reinforced Concrete structures. One of the important constituent of Reinforced Concrete structures are steel reinforcements. This high use of reinforcement causes stress both in terms of cost and also over natural resources of our country viz., iron ore. The main purpose of this project is to reduce the reinforcement in concrete beams by altering their configurations. The effective load carrying capacity of beams with different configurations are tested and compared. At the end of this experiment the most effective reinforcement configuration for beams can be figured out.
\end{abstract}

Keywords: laced beams, Sandwiched beam composites, Reinforced beams.

\section{INTRODUCTION}

The current scenario of infrastructure boom in the country, the demands of steel reinforcement is on the rise. This causes a great stress on financial and natural resources. India is now the third largest crude steel producers. In this experiment we aim to reduce the steel reinforcement in beams by providing lacing in place of stirrups.

\section{METHODOLOGY}

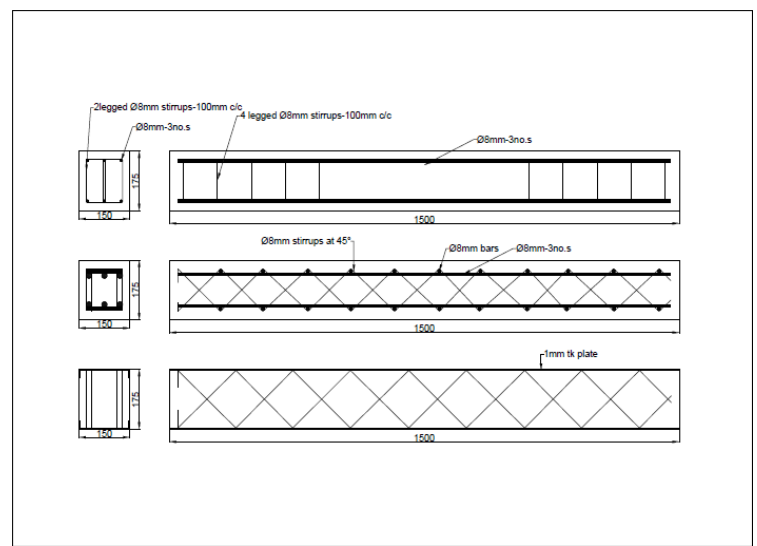

Figure showing diagrammatic representation of reinforcement of beams

Three beams are cast with different reinforcement detailing as shown in the figure. Beam 1 is a conventional beam with $8 \mathrm{~mm}$ diameter bars at top and bottom, with $8 \mathrm{~mm}$ diameter stirrups at $100 \mathrm{~mm} \mathrm{c/c}$ spacing. In Beam 2, the stirrups are replaced with lacings provided at $45^{\circ}$ to the horizontal. In Beam 3, the top and bottom reinforcement are replaced with steel sheets of equivalent cross sectional area of that of bars i.e., $1 \mathrm{~mm}$ thick plates. The numerical models

Revised Manuscript Received on August 19, 2019.

Bharanidhar.T.S,Post graduate student, Department of civil engineering,Kumaraguru College of Technology,Coimbatore. T.N, India

DrP.Eswaramoorthi, Professor,Department of civil engineering,Kumaraguru College of Technology,Coimbatore.T.N, India for the above beams are developed by ANSYS software and is to be given two point loading. And their resultant behaviour is studied in detail.

\section{STRUCTURAL BEHAVIOUR OF COMPOSITE BEAM}

The transfer of load in beam is based on two factor viz., strength of bond between cover plate and concrete, transfer of load from cover plate to concrete core. The beams when subjected to load is expected to act like a strut and tie model. The lacings like welded bars in the sandwich composite beam will transfer the loads between concrete plates even when the core concrete is totally disintegrated. The steel plates act as confinement to concrete core and prevent spalling of core concrete. Bottom plate will be experiencing tension, while top plate experiences compression.

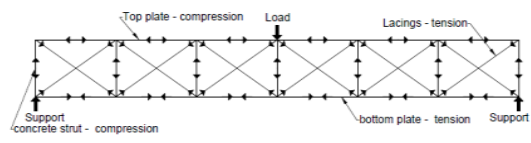

NUMERICAL MODELLING

The numerical models for the described beams are developed using ANSYS software. The concrete grade is given as M25 and Fe415 steel values are used. The beam is subjected to two point loading to find the ultimate load at which all three beams fail.

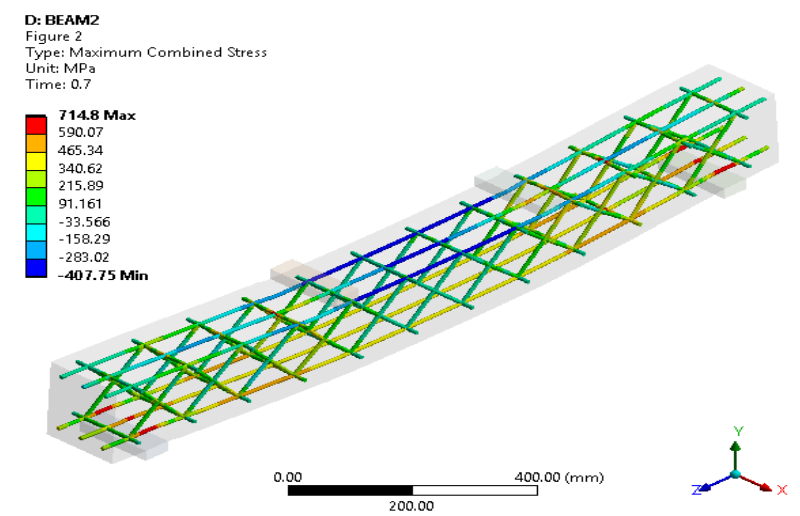

Beam 2 reinforcement stress after loading 


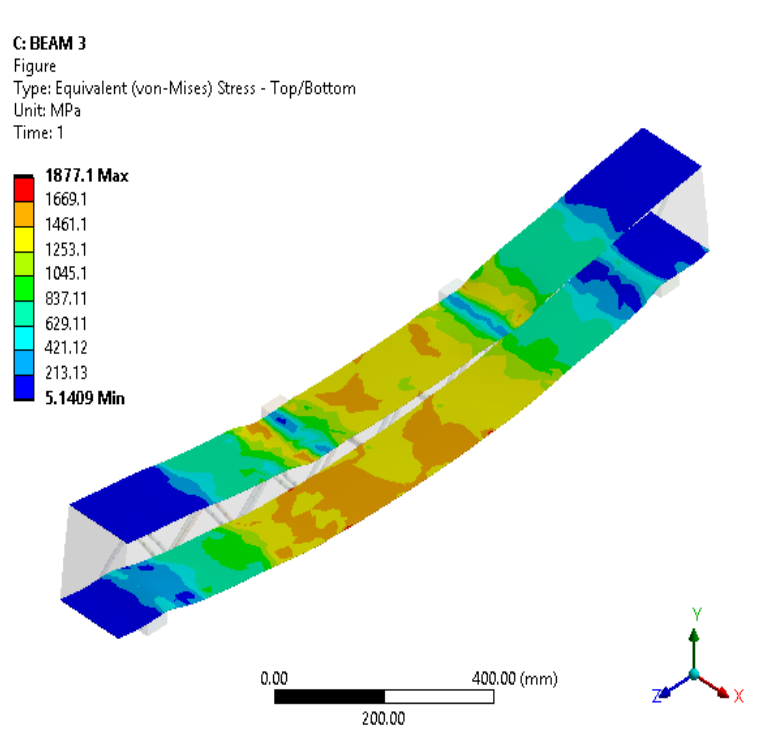

Beam 3 stress at top and bottom plates

\section{RESULTS AND DISCUSSION}

The results of the numerical analysis of the three beams tested with their deflection parameters are as follows.

\begin{tabular}{|c|c|c|c|c|c|}
\hline \multicolumn{2}{|c|}{ BEAM 1 } & \multicolumn{2}{c|}{ BEAM 2 } & \multicolumn{2}{c|}{ BEAM 3 } \\
\hline Def(mm) & $\begin{array}{c}\text { load } \\
(\mathrm{KN})\end{array}$ & $\begin{array}{c}\text { Def } \\
(\mathrm{mm})\end{array}$ & $\begin{array}{c}\text { load } \\
(\mathrm{KN})\end{array}$ & $\begin{array}{c}\text { Def } \\
(\mathrm{mm})\end{array}$ & $\begin{array}{c}\text { load } \\
(\mathrm{KN})\end{array}$ \\
\hline 0 & 0 & 0 & 0 & 0 & 0 \\
\hline 1.1546 & 35.906 & 2.3088 & 47.852 & 2.307 & 57.19 \\
\hline 2.2953 & 49.894 & 4.5414 & 65.698 & 4.5656 & 82.199 \\
\hline 3.4119 & 60.252 & 6.7154 & 77.407 & 6.7818 & 101.96 \\
\hline 4.5129 & 68.448 & 8.8503 & 85.387 & 8.9706 & 119.63 \\
\hline 5.5913 & 74.116 & 10.968 & 91.459 & 11.137 & 136.51 \\
\hline & & 15.197 & 100.47 & 13.282 & 152.91 \\
\hline
\end{tabular}

Table showing load and deflection for tested beams.

The graph corresponding to the load-deflection values for all three beams is plotted and is represented below.

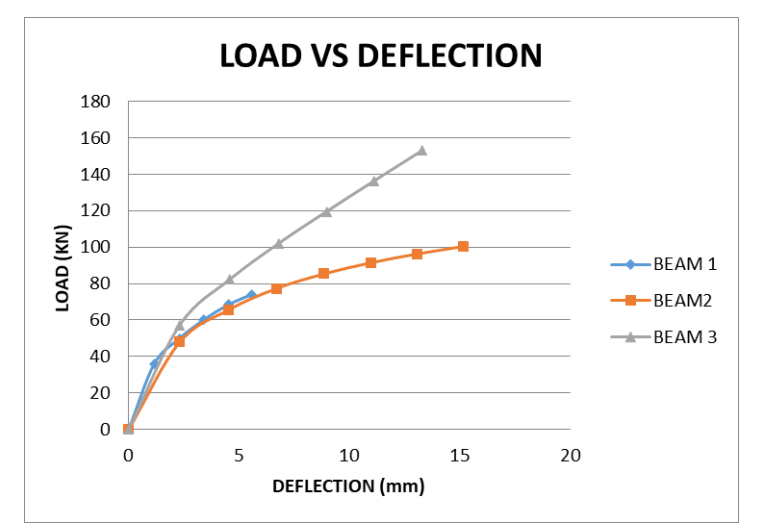

From the above results it can be observed that Beam 3 has more load capacity than Beam 2 which in turn is greater than Beam 1. The ultimate load of Beam 3 is $152.91 \mathrm{kN}$ which is two times greater than beam 1 which has a value of $74.116 \mathrm{kN}$. The ultimate load carrying capacity of the beam is compared in the following chart.

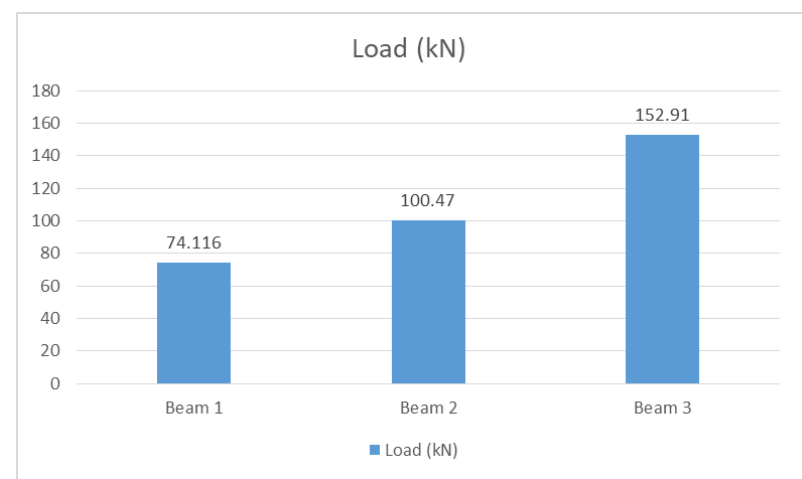

Chart depicting ultimate load for the beams.

The length of stirrup reinforcement in Beam 1,2,3 are $10.5 \mathrm{~m}, 8.6 \mathrm{~m}, 8.7 \mathrm{~m}$ respectively. Thus we are able to achieve higher load carrying capacity with lower reinforcement length as stirrups. Thus the capital cost of construction can be reduced. The reinforcement usage is roughly decreased by $20 \%$ in Beam 2 and 3 as compared to beam 1 .

\section{LIMITATIONS}

- Though Beam 3 has higher load carrying capacity, it is a difficult task to cast beams with such reinforcement arrangement with top and bottom plates. Thus beam 3 is much suitable for precast elements than in-situ concreting.

- In beam 3 the top and bottom plates are exposed to outer environment than being protected by concrete core. Hence they should be provided necessary protective coatings and be avoided in places with severe exposure conditions.

- Bending the bars at prescribed inclination is tiresome and labour intensive process and should be proceeded with utmost caution.

\section{REFERENCES}

1. Thirumalaiselvi, and N. Anandavalli, Numerical investigations on static response of laced steel-concrete composite slabs, Proceedings of Intl. conf. on advances in civil, structural and mechanical engineering, Hong Kong, 2013, 37-41.

2. M. Xie, N. Foundoukos, and J.C. Chapman, Static tests on steel - concrete- steel sandwich beams, Journal of Construction Steel Research,63(6), 2007, 735-750.

3. S. RoohollahMousavi, and M. RzaEsfahani, Effective moment of inertia prediction of FRP-reinforced concrete beams based on experimental results, Journal of composites for construction, 16, 2012, 490-498.

4. N. Anandavalli, N. Lakshmanan, G.M. Samuel Knight, Nagesh R. Iyer, and J. Rajasankar, Performance of Laced Steel-Concrete Composite (LSCC) beams under monotonic loading, Engineering Structures, 41, 2012, 177-185. 